\title{
Morphometric evaluation of nasolacrimal duct
}

\author{
Burcu Erçakmak Güneş ${ }^{1}$ (D) , Alper Vatansever ${ }^{2}$ (D), Deniz Demiryürek ${ }^{1}$ (D), Ekim Gümeler ${ }^{3}$ (D) \\ ${ }^{1}$ Department of Anatomy, Faculty of Medicine, Hacettepe University, Ankara, Turkey \\ ${ }^{2}$ Department of Anatomy, Faculty of Medicine, Bahkesir University, Balikesir, Turkey \\ ${ }^{3}$ Department of Radiology, Faculty of Medicine, Hacettepe University, Ankara, Turkey
}

\begin{abstract}
Objectives: Obstructions are very commonly seen in nasolacrimal duct before it opens into the inferior nasal meatus. Detailed anatomical knowledge of the nasolacrimal duct is crucial for physicians to understand the etiology of the obstructions, to plan ideal management option and to reduce unexpected iatrogenic injuries during surgeries. The aim of this study was to investigate morphometric properties of the nasolacrimal duct on computed tomography images.
\end{abstract}

Methods: Three-dimensional computed tomography (3D-CT) of 142 adults (65 females, 77 males) were retrospectively evaluated. Antero-posterior cranial diameter, antero-posterior and transverse diameters and vertical angle of the nasolacrimal duct, distance between distal end of the nasolacrimal duct to anterior surface of the maxilla were measured and the differences evaluated statistically between right and left sides and among females and males and among different ages. All measurements were done using Osirix-Lite version 9 software.

Results: None of the morphometric parameters of the nasolacrimal duct showed significant differences between right and left sides. Antero-posterior cranium and transverse diameter of the nasolacrimal duct were longer in men than women.

Conclusion: Determining to morphometric properties of the nasolacrimal canal has advantages for understanding the etiology of the NLD obstructions, deciding the ideal surgical technique and reducing to unexpected injuries during surgeries related with this region.

Keywords: 3D reconstruction; anatomy; computed tomography; nasolacrimal duct

Anatomy 2021;15(1):64-68 @2021 Turkish Society of Anatomy and Clinical Anatomy (TSACA)

\section{Introduction}

Nasolacrimal duct (NLD) begins from the lacrimal sac and continues as the bony nasolacrimal duct between the lacrimal bone and maxilla. It drains into nasal cavity at the level of inferior nasal meatus. The NLD is entirely surrounded by the maxilla. ${ }^{[1]}$

The obstructions of the NLD are seen frequently, due to its shape. The obstructions can be either congenital or acquired. In each instance, the etiology and the prognosis is different. ${ }^{[2]}$ There are different options for the management of the obstruction; non-surgical or surgical. ${ }^{[3,4]}$ Detailed anatomical knowledge is of great clinical importance for to understand the etiology of the obstruction and the success of treatment techniques. There are numbers of studies that are evaluating the morphometric properties of the NLD. ${ }^{[5-7]}$ The NLD has different anthropometric characteristics among populations. ${ }^{[1,47-9]}$ Avdagic et al.$^{[10]}$ indicated that NLD obstruc- tions could count as an important etiologic factor of epiphora, and emphasized that selecting criteria for treating these obstructions depends on its anatomical properties.

Considering craniometric features of the NLD during a surgical treatment is of great importance for a successful surgery and improving quality of post-operative period; the aim of this study was to examine detailed morphometric properties of the NLD according to its craniometric characteristics.

\section{Materials and Methods}

Computed tomography (CT) images of 142 adults (65 females, 77 males) who admitted to Hacettepe University Hospital without a significant pathology or previous surgery in the head region were retrospectively evaluated in the study. The mean age of participants was 60.02 (range: 27-85) years. DICOM series of CT images were recon- 
structed three-dimensionally (3-D) using free licensed Osirix Lite Software v.12.0.1. Participants who undergone the CT for any reason other than trauma or interventional applications in their orbit, nose or paranasal sinuses were included in the study. Participants who had bone disorders, trauma history, and neoplasms in related regions were excluded from the study.

A 64-detector-row dual-source CT scanner (SOMATOM Definition, Siemens Healthcare, Erlangen, Germany) was used for CTA imaging. The protocol was as follows: $64 \times 0.6$ collimation, 1.4 pitch, 0.5 -s rotation time, $100 \mathrm{kV}$ (peak), and 180 effective $\mathrm{mAs}$. The source images were reconstructed into 1-mm slice thicknesses in axial view, and coronal and sagittal images were reformatted. All CT images were obtained from the Picture Archiving and Communication System

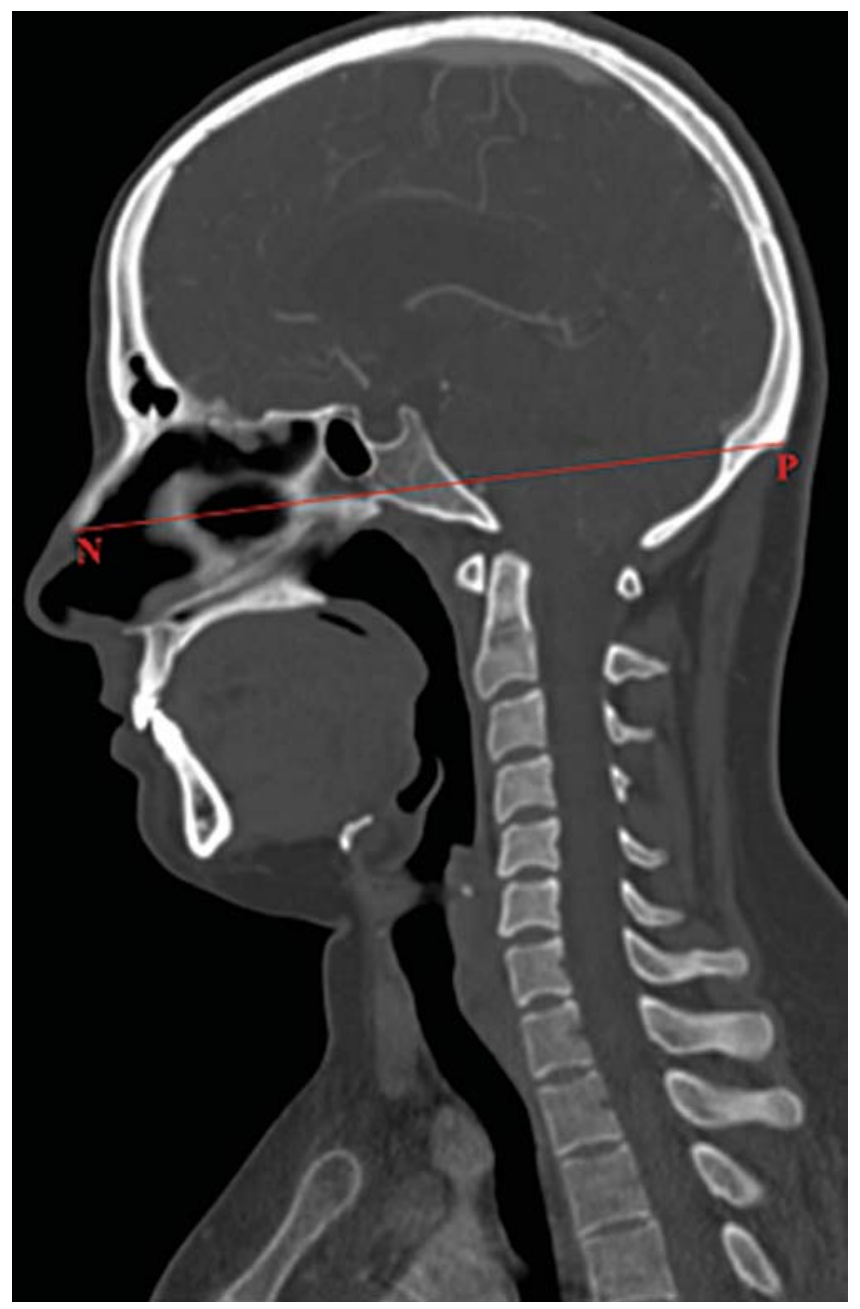

Figure 1. Computed tomography image, midsagittal section. N: tip of the nasal bone; P: external occipital protuberance; red line: distance between tip of nasal bone and external occipital protuberance defining antero-posterior diameter of the cranium.
(PACS) of the authors' University Hospital. A 20-year experienced anatomy professor, 14-year and 7-year experienced anatomy specialists and a 10-year experienced radiology specialist using Osirix Lite v.12.0.1 completed all measurements.

CT image series were set in same anatomical planes using 3-D multiplanar reconstruction (MPR) tool of Osirix Lite software. Distance between tip of nasal bone and the external occipital protuberance was calculated as antero-posterior diameter of the cranium in the midsagittal sections (Figure 1). Furthermore, in sagittal sections distances from the distal end of NLD to anterior surface of maxilla were measured bilaterally (Figure 2). Anteroposterior and transverse diameters of NLD were measured bilaterally on the axial sections where the inferior orbital margins were detected (Figure 3). Angle between

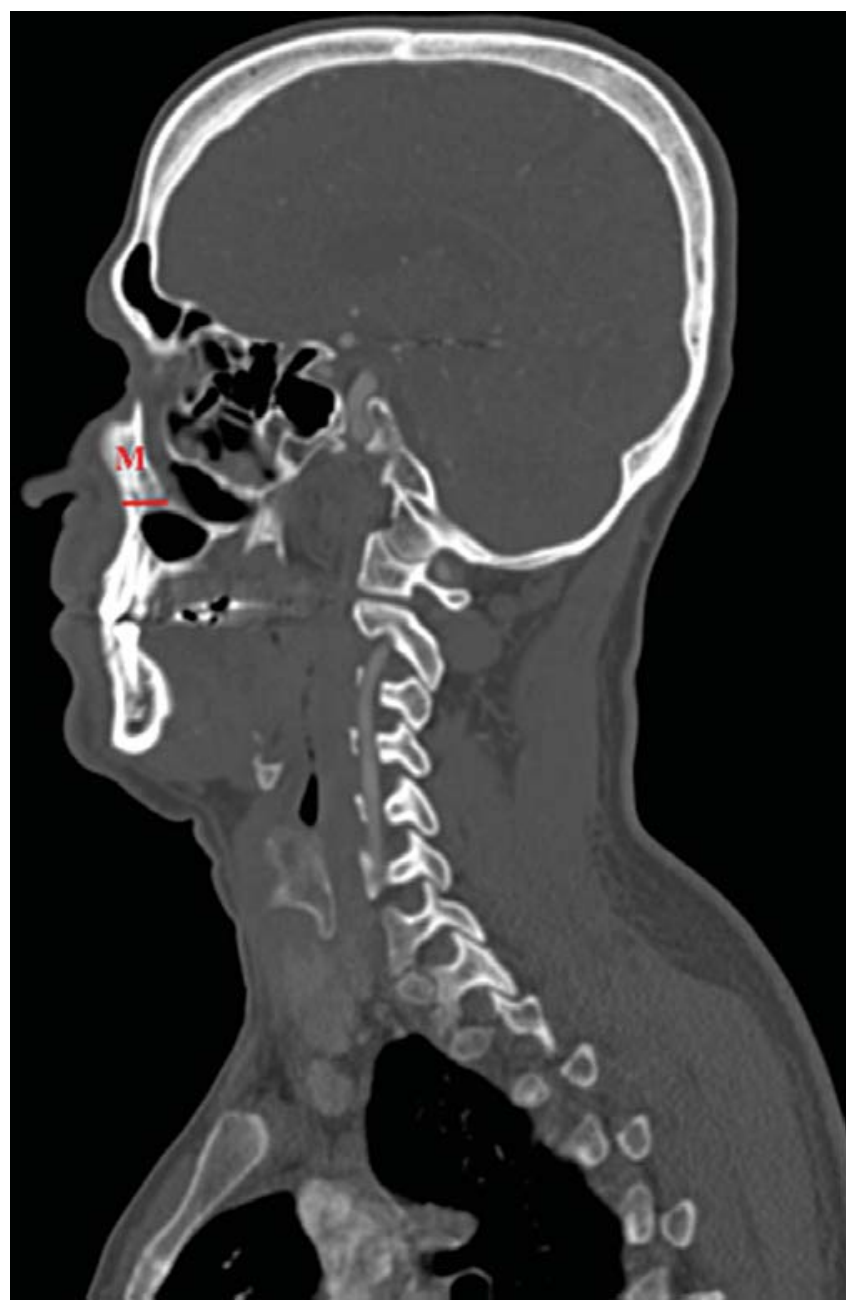

Figure 2. Computed tomography image, sagittal section. M: maxilla; red line: distance between opening of nasolacrimal duct and anterior wall of the maxilla. 
proximal and distal ends of the NLD according to vertical axis were also measured bilaterally in sagittal sections.

Statistical analysis were performed using SPSS version 23 (SPSS Inc., Chicago, IL, USA). All morphometric parameters were examined using histograms and probability plots. The Kolmogrov-Smirnov test and the Shapiro-Wilk test used to define normality distribution of the data. Descriptive analyses were used for demonstrating the means and standard deviations of all measurements. The student $\mathrm{t}$-test and the Mann-Whitney $\mathrm{U}$ test were utilized for comparison of measured parameters between genders and ages. Paired student's t test and Wilcoxon test was performed for normal and non-normal distributed parameters, respectively to compare measured variables between left and right sides. Pearson test for normally distributed parameters and Spearman's rho test for non-normally distributed parameters were used to investigate associations between parameters with calculating correlation coefficients and their significance at a 5\% Type-I error level. Variables with a p value of less than 0.05 were considered statistically significant.

\section{Results}

The mean antero-posterior cranium diameter was 17.97 \pm 0.07 (range: 15.96-20.15) $\mathrm{cm}$. The narrowest antero-posterior diameter of the NLD was measured as $2.71 \mathrm{~mm}$, while the narrowest transverse diameter of the NLD was $1.99 \mathrm{~mm}$. The angle between the proximal end

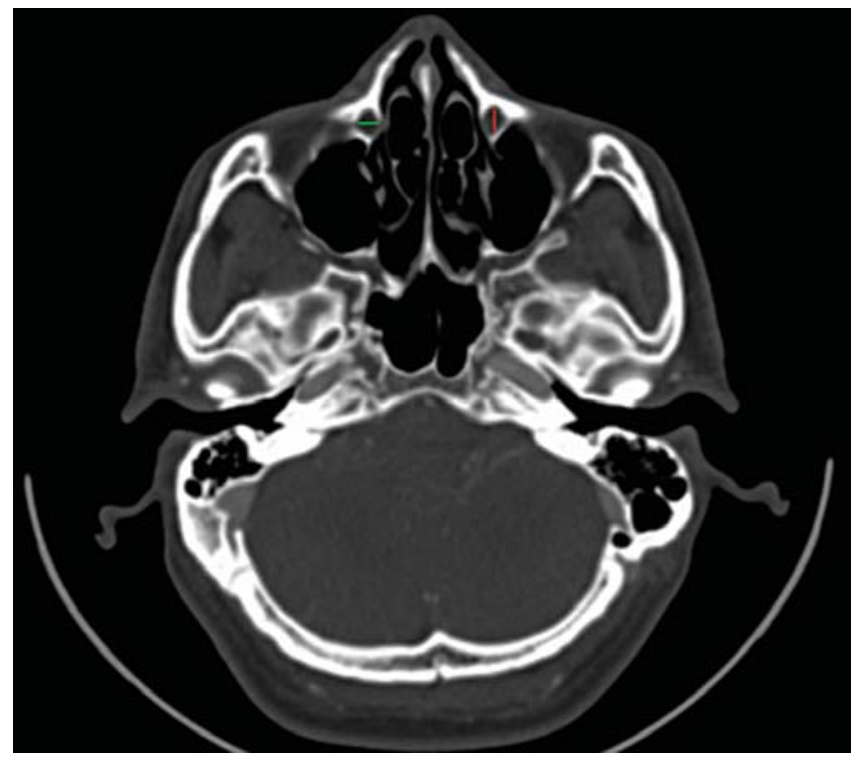

Figure 3. Computed tomography image, axial section. Green line: transverse diameter of the NLD (nasolacrimal duct); red line: anteroposterior diameter of the nasolacrimal duct.

and the distal end of the NLD was $0.87^{\circ}$ to $29.14^{\circ}$, varying in a very wide range. Mean values, standard deviations, and minimum-maximum values of all measured parameters were demonstrated in Table 1. None of morphometric parameters demonstrated significant difference between right and left sides.

Table 1

Results of the measurements.

\begin{tabular}{|c|c|c|c|c|}
\hline Parameters & Sex & Side & Mean \pm SD & Min-max \\
\hline \multirow[t]{4}{*}{ Antero-posterior diameter of NLD (mm) } & $\mathrm{F}$ & $\mathrm{R}$ & $4.67 \pm 0.12$ & $2.83-7.04$ \\
\hline & & $\mathrm{L}$ & $4.67 \pm 0.12$ & $2.96-7.51$ \\
\hline & M & $\mathrm{R}$ & $5.09 \pm 0.13$ & $2.71-7.87$ \\
\hline & & L & $4.95 \pm 0.1$ & $2.79-7.29$ \\
\hline \multirow[t]{4}{*}{ Transverse diameter of NLD (mm) } & $\mathrm{F}$ & $\mathrm{R}$ & $3.81 \pm 0.08$ & $2.43-5.66$ \\
\hline & & $\mathrm{L}$ & $3.74 \pm 0.09$ & $1.99-6.43$ \\
\hline & M & R & $4.2 \pm 0.09$ & $2.03-6.43$ \\
\hline & & L & $4.15 \pm 0.09$ & $2.76-6.34$ \\
\hline \multirow[t]{4}{*}{ Angle of NLD (mm) } & $\mathrm{F}$ & R & $13.61 \pm 0.65$ & $5.53-29.14$ \\
\hline & & $\mathrm{L}$ & $13.98 \pm 0.61$ & $5.68-27.24$ \\
\hline & M & $\mathrm{R}$ & $12.83 \pm 0.62$ & $0.87-23.92$ \\
\hline & & L & $12.25 \pm 0.59$ & $4.18-27.89$ \\
\hline \multirow[t]{4}{*}{ Distance to anterior face of maxilla $(\mathrm{cm})$} & $\mathrm{F}$ & $\mathrm{R}$ & $0.91 \pm 0.02$ & $0.48-1.53$ \\
\hline & & $\mathrm{L}$ & $0.89 \pm 0.03$ & $0.33-1.64$ \\
\hline & M & $\mathrm{R}$ & $0.97 \pm 0.03$ & $0.45-1.71$ \\
\hline & & L & $0.97 \pm 0.03$ & $0.35-2.27$ \\
\hline
\end{tabular}

F: female; L: left; M: male; NLD: nasolacrimal duct; R: right; SD: standard deviation. 
Antero-posterior and transverse diameters of proximal end of NLD had positive and statistically significant correlation with antero-posterior diameter of cranium (right side; antero-posterior diameter, $\mathrm{r}=0.226, \mathrm{p}<0.001$; transverse diameter, $\mathrm{r}=0.231, \mathrm{p}<0.001$. Left side; anteroposterior diameter, $\mathrm{r}=0.203, \mathrm{p}<0.001$; transverse diameter, $\mathrm{r}=0.286, \mathrm{p}<0.001)$.

Antero-posterior cranium diameter was longer in men than women $(\mathrm{p}<0.001)$. Transverse diameters of proximal end of the NLD on both sides were wider in men than women $(\mathrm{p}<0.001)$. However, the angle between proximal and distal ends of the NLD was wider in women than men $(\mathrm{p}=0.02)$.

The angle between proximal and distal ends of NLD of the right sides had negative and statistically significant correlation with age $(\mathrm{r}=-0.195, \mathrm{p}=0.02)$. Furthermore, distance between distal end of NLD and anterior surface of maxilla on right sides had negative and statistically significant correlation with age, as well $(\mathrm{r}=-0.178, \mathrm{p}=0.03)$. The angle between proximal and distal ends of the NLD had negative and statistically significant correlation with age among women $(\mathrm{r}=-0.272, \mathrm{p}=0.02)$. In men, the distance between the distal end of the NLD and anterior surface of maxilla on right side had negative and significant correlation with age $(\mathrm{r}=-0.305, \mathrm{p}<0.001)$.

\section{Discussion}

We evaluated the morphometric properties of the NLD and compared these measured parameters between genders. Furthermore, we investigated the effects of age on these morphometric parameters.

The morphometry of the NLD had been a subject of numerous cadaveric studies. ${ }^{[4,711-14]}$ These studies aimed to evaluate morphometric properties of the NLD in different populations using cadaveric specimens. Computed tomography studies purposed determining the NLD anatomy in different patient groups such as NLD obstructions and craniofacial malformations. ${ }^{[15-20]}$ A great number of studies focused on the NLD pathologies indicated the importance of anatomical knowledge for increasing quality of surgeries and post-operative period of patients. Besides these clinical studies, there were a few radiologic studies focusing on morphometry of the NLD. ${ }^{[1,5,6,21]}$ Ela et al. ${ }^{[6]}$ studied the morphometry of NLD on children, while Czyz et al. ${ }^{[5]}$ examined the NLD morphometry according to aeration grades in adult participants. However, they could not find any significant differences for morphometric values of the NLD between age and genders. In contrast to their results, our data demonstrated statistically significant differences between gender for antero-posterior diameter of the NLD in favor of men. Furthermore, our results demonstrated that NLD's vertical angle and distance of the distal end of the NLD to anterior surface of the maxilla on the right side were getting lower with increase in age.

According to our knowledge, there is only one study that evaluated the NLD morphometry according to craniometrical properties. ${ }^{[2]}$ However, participants included in that study had acquired NLD obstructions, thus, anatomical characteristics may show differences since pathologic condition could affect the other structures. We evaluated the relationship between antero-posterior diameter of cranium and morphometric parameters in healthy adult participants. Our results indicated that only antero-posterior diameter of proximal end of the NLD had significant positive correlation with the antero-posterior cranium diameter.

Craniofacial anomalies, such as thickening of nasal mucosa, septal deviations, hypertrophic concha, immature maxilla, cleft lip/plate could lead nasal airway obstructions. Altun et al. ${ }^{[15]}$ compared nasolacrimal duct morphometry between patients who had unilateral cleft lip/plate and healthy participants. They revealed that nasolacrimal duct diameters were narrower in craniofacial anomaly patients. However, they did not find any statistical differences in any parameters between gender in both craniofacial anomaly and control groups. ${ }^{[15]}$ In contrast to their study, our results demonstrated the transverse diameter and vertical angle of the NLD was longer in men. The reason of these differences may be due to the mean age of participants. The main limitation of the study is that it could not be compared with cadaveric evaluation.

\section{Conclusion}

In the present study, we evaluated morphometric values of the NLD on healthy adult participants. According to our results, some of the morphometric parameters demonstrated statistically significant differences between genders and age. We suggest that our findings would be helpful to understand the nature of NLD obstructions and to avoid unexpected injuries during surgical approaches.

\section{Conflict of Interest}

Authors have no conflict of interest to declare.

\section{Author Contributions}

BEG: project development, data analyses, manuscript writing; AV: project development, data collection, data analyses, manuscript writing; DD: project development, data analyses, manuscript editing; EG: data collection, data analyses, manuscript writing. 


\section{Ethics Approval}

Ethics approval for this study was obtained from Institutional Ethical Board (Decree No: 2020/20-16).

\section{Funding}

This research did not receive any specific grant from funding agencies in the public, commercial, or not-for-profit sectors.

\section{References}

1. Lee S, Lee UY, Yang SW, Lee WJ, Kim DH, Youn KH, Kim YS. 3D morphological classification of the nasolacrimal duct: anatomical study for planning treatment of tear drainage obstruction. Clin Anat 2021;34:624-33.

2. Heichel J, Struck HG, Viestenz A, Hammer T, Viestenz A, Fiorentzis $M$. Anatomic landmarks in lacrimal surgery from an ophthalmologist's point of view: clinical findings of external dacryocystorhinostomy and dacryoendoscopy. Clin Anat 2017;30:1034-42.

3. Narioka J, Matsuda S, Ohashi Y. Correlation between anthropometric facial features and characteristics of nasolacrimal drainage system in connection to false passage. Clin Exp Ophthalmol 2007; 35:651-6.

4. Valencia MRP, Takahashi Y, Naito M, Nakano T, Ikeda H, Kakizaki H. Lacrimal drainage anatomy in the japanese population. Ann Anat 2019;223:90-9.

5. Czyz CN, Bacon TS, Stacey AW, Cahill EN, Costin BR, Karanfilov BI, Cahill KV. Nasolacrimal system aeration on computed tomographic imaging: sex and age variation. Ophthalmic Plast Reconstr Surg 2016;32:11-6.

6. Ela AS, Cigdem KE, Karagoz Y, Yigit O, Longur ES. Morphometric measurements of bony nasolacrimal canal in children. J Craniofac Surg 2018;29:e282-7.

7. Takahashi Y, Nakamura Y, Nakano T, Asamoto K, Iwaki M, Selva D, Leibovitch I, Kakizaki H. The narrowest part of the bony nasolacrimal canal: an anatomical study. Ophthalmic Plast Reconstr Surg 2013;29:318-22.

8. Okumus O. Investigation of the morphometric features of bony nasolacrimal canal: a cone beam computed tomography study. Folia Morphol (Warsz) 2020;79:588-93.

9. Shigeta K, Takegoshi H, Kikuchi S. Sex and age differences in the bony nasolacrimal canal: an anatomical study. Arch Ophthalmol 2007;125:1677-81.
10. Avdagic E, Phelps PO. Nasolacrimal duct obstruction as an important cause of epiphora. Dis Mon 2020;66:101043.

11. Ali MJ, Schicht M, Paulsen F. Morphology and morphometry of lacrimal drainage system in relation to bony landmarks in caucasian adults: a cadaveric study. Int Ophthalmol 2018;38:2463-9.

12. Elshaarawy EA. Morphological and morphometrical study of the nasal opening of nasolacrimal duct in man. Folia Morphol (Warsz) 2014;73:321-30.

13. Takahashi Y, Kakizaki H, Nakano T. Bony nasolacrimal duct entrance diameter: gender difference in cadaveric study. Ophthal Plast Recons 2011;27:204-5.

14. Park J, Takahashi Y, Nakano T, Asamoto K, Iwaki M, Selva D, Leibovitch I, Yang SW, Kakizaki H. The orientation of the lacrimal fossa to the bony nasolacrimal canal: an anatomical study. Ophthalmic Plast Reconstr Surg 2012;28:463-6.

15. Altun O, Dedeoglu N, Avci M. Examination of nasolacrimal duct morphometry using cone beam computed tomography in patients with unilateral cleft lip/palate. J Craniofac Surg 2017;28:e725-8.

16. Bulbul E, Yazici A, Yanik B, Yazici H, Demirpolat G. Morphometric evaluation of bony nasolacrimal canal in a caucasian population with primary acquired nasolacrimal duct obstruction: a multidetector computed tomography study. Korean J Radiol 2016;17:271-6.

17. Takahashi Y, Nakata K, Miyazaki H, Ichinose A, Kakizaki H. Comparison of bony nasolacrimal canal narrowing with or without primary acquired nasolacrimal duct obstruction in a japanese population. Ophthal Plast Recons 2014;30:434-8.

18. Park JH, Huh JA, Piao JF, Lee H, Baek SH. Measuring nasolacrimal duct volume using computed tomography images in nasolacrimal duct obstruction patients in Korean. Int J Ophthalmol 2019;12:100 5.

19. Choi SC, Lee S, Choi HS, Jang JW, Kim SJ, Lee JH. Preoperative computed tomography findings for patients with nasolacrimal duct obstruction or stenosis. Korean J Ophthalmol 2016;30:243-50.

20. Zhang C, Yu G, Cui Y, Wu Q, Wei W. Anatomical characterization of the nasolacrimal canal based on computed tomography in children with complex congenital nasolacrimal duct obstruction. J Pediatr Ophthalmol Strabismus 2017;54:238-43.

21. Lin Z, Kamath N, Malik A. High-resolution computed tomography assessment of bony nasolacrimal parameters: variations due to age, sex, and facial features. Orbit 2020;16:1-6.

22. Lee JS, Lee H, Kim JW, Chang M, Park M, Baek S. Association of facial asymmetry and nasal septal deviation in acquired nasolacrimal duct obstruction in East Asians. J Craniofac Surg 2013;24:1544-8.

Correspondence to: Burcu Erçakmak Güneș, MD

B. Erçakmak Günes 0000-0001-6936 A. Vatansever 0000-0002-3632-1020 D. Demiryürek 0000-0001-8781-1719; E. Gümeler 0000-0003-3783-2372

deomed.
Department of Anatomy, Faculty of Medicine, Hacettepe University, Ankara, Turkey

Phone: +905324930005

e-mail: burcue@hacettepe.edu.tr

Conflict of interest statement: No conflicts declared.

This is an open access article distributed under the terms of the Creative Commons Attribution-NonCommercial-NoDerivs 4.0 Unported (CC BY-NCND4.0) Licence (http://creativecommons.org/licenses/by-nc-nd/4.0/) which permits unrestricted noncommercial use, distribution, and reproduction in any medium, provided the original work is properly cited. How to cite this article: Erçakmak Güneş B, Vatansever A, Demiryürek D, Gümeler E. Morphometric evaluation of nasolacrimal duct. Anatomy 2021;15(1):64-68. 